\title{
A relação entre música e texto nos madrigais de Carlo Gesualdo - um estudo sobre seu amadurecimento ao longo da obra
}

\author{
Rafael Garbuio (UNICAMP) \\ Carlos Fiorini (UNICAMP)
}

Resumo: A música do período do Renascimento encontrou no gênero madrigal seu principal meio de desenvolvimento. Através desse gênero de composição as ideias humanistas e a produção poética feita a partir dela influenciaram a escrita musical. Neste contexto, encontramos a obra do compositor italiano Carlo Gesualdo, que teve grande proximidade com poetas e suas obras. No decorrer do desenvolvimento de sua carreira como compositor e por conta do amadurecimento de sua escrita a relação música/texto se estreitou a tal ponto que Gesualdo passou a escrever ele próprio os textos que iriam servir a seus madrigais mais tardios. A proposta deste artigo é entender o processo do desenvolvimento dessa relação entre seus primeiros madrigais até os últimos exemplos.

Palavras-chave: Renascimento, Madrigais Italianos, Textos, Carlo Gesualdo.

THE RELATIONSHIP BETWEEN MUSIC AND TEXT OF CARLO GESUALDO'S MADRIGALS - A STUDY ON THE DEVELOPMENT ALONG HIS WORK

\begin{abstract}
The music of the Renaissance period had in the madrigal genre its primary means of development. Through this composition form, humanistic ideas and poetic production influenced musical writing. Within this context we find the work of Italian composer Carlo Gesualdo. He had great proximity to poets and their works. During the development of his career as a composer and the maturing of his writing Gesualdo went on to write his own texts. The purpose of this article is to understand the progress of this relationship between music and text.
\end{abstract}

Keywords: Renaissance, Italian Madrigals, Texts, Carlo Gesualdo. 


\section{Introdução}

O compositor italiano Carlo Gesualdo está inserido na fase final do Renascimento. Sua produção musical concentrou-se em motetos sacros e madrigais italianos, nestes últimos temos as obras que o tornaram mais conhecido. Seus seis livros de madrigais a cinco vozes apresentam a sofisticação de uma linguagem musical específica a esse compositor e alguns de seus contemporâneos.

A obra de Gesualdo apresenta características técnicas que a distingue do repertório mais conhecido deste período. Sua escrita virtuosística, suas inovações harmônicas e a constante ousadia na escrita vocal fizeram de Gesualdo um estilo a parte do Renascimento. A especificidade de seus procedimentos técnicos levou sua música a ser pouco executada nos séculos seguintes à sua produção, e até pouco tempo atrás ainda estava reservada a ser exemplo de exageros do período e até mesmo representar a fase decadente da época. Um dos motivos pelos quais o repertório caiu quase que no esquecimento foi a dificuldade em compreender seus procedimentos musicais por parte dos estudiosos e mesmo dos músicos, além da dificuldade em se classificar este repertório.

Nomear a obra de Gesualdo simplesmente como música do Renascimento gera uma série de dúvidas estilísticas, principalmente devido a suas características musicais repletas de excessos expressivos e do tratamento harmônico não usual. Ao passo que, tentar antecipar no seu repertório características do período Barroco torna ainda mais confusa a tarefa, por conta das bases polifônicas presentes na formação do compositor e por sua influência humanista. O caminho teórico para a solução deste problema começou a ser encontrado há pouco mais de 40 anos, quando alguns estudiosos do assunto, como Glenn Watkins, Maria Rika Maniates e Edward Lowinsky, passaram a classificar o repertório final do Renascimento em um segmento à parte do período, com uma escrita mais tardia e procedimentos mais complexos.

Algumas outras classificações vieram junto com esse entendimento tardio do Renascimento e ajudaram na compreensão estética do repertório. Uma dessas classificações foi a aceitação do conceito de Maneirismo artístico aplicado a esse repertório. Este estilo, que é encontrado na produção artística do final do 
Renascimento, teve seu berço nas artes visuais. O historiador de arte Arnold Hauser foi o principal teórico a dedicar seu estudo a entender esse tema. 0 resultado de seu trabalho trouxe importante contribuições para o entendimento do período. Segundo Hauser, pintores como Jacopo Pontormo (1494-1557) e Andrea del Sarto (1515-1516) são utilizados como exemplos de obras carregadas de artificialismo e virtuosidade técnica que passaram a dominar o ambiente estético do final do período do Renascimento (1976, p. 17). Neste contexto, identificou-se um outro estilo, caracterizado pelos excessos e pelo pessimismo refletidos na arte. A essa produção artística atribui-se a classificação de Maneirismo artístico. Carlo Gesualdo passou a ser considerado por esses estudiosos como um representante do Maneirismo em música, e suas características passaram a ser analisadas não mais como parte dos procedimentos gerais do Renascimento. (Hocke, 2005, p. 296)

Diante destas novas compreensões e do surgimento de um novo interesse por esse repertório, certos aspectos técnicos da escrita musical passaram a ser entendidos de forma mais abrangente. Um dos pontos centrais dessas novas visões foi que a escrita musical de Gesualdo encontra-se no ápice da transição modal/tonal. (Lowinsky, 1961, p. 39) Nesta transição, que está presente ao longo de todo o repertório musical do Renascimento, muitos processos de experimentações harmônicas realizados pelos compositores resultaram em novos caminhos que levaram a prática musical de um sistema de composição para outro. Esses experimentos tornaram-se para Gesualdo o principal meio de concepção artística, ou seja, o compositor os utilizava como fonte de criatividade. Essa constatação é essencial para análise musical da sua obra.

Uma das contribuições mais significativas dos recentes estudos está na maior atenção dada ao tratamento textual da obra, procedimento que tem se mostrado eficiente no entendimento do repertório. Através de um estudo cuidadoso sobre a narração proposta pelo texto e as imagens criadas por ele, desvenda-se com mais clareza as intenções musicais dos compositores que, na maioria das vezes, coloca sua música a serviço do texto, tentando recriar suas imagens. 
A partir dos conhecimentos que dispomos sobre a poesia e os poetas do Renascimento, e uma análise direcionada sobre este tema nos madrigais de Gesualdo, temos condições de aprofundar o entendimento dos textos utilizados pelo compositor e investigar melhor suas intenções e realizações musicais.

\section{A relação textual}

A relação entre música e texto apresenta-se como um dos pontos de grande interesse nas análises dos madrigais de Gesualdo, por ser através dela que se entende os demais procedimentos musicais empregados pelo compositor. A construção musical das peças está diretamente ligada às imagens e narrações que o poema descreve, tornando-se o principal ponto de apoio na concepção da música (Einstein, 1971, p. 166). Diante dessa importância, faz-se necessário um estudo sobre a manipulação dos textos e seu desenvolvimento ao longo dos livros de madrigais.

Os primeiros de seus seis livros tiveram as obras escritas a partir de textos de poetas contemporâneos a ele. Esse procedimento limitava a forma como o compositor poderia manipular seus versos, visto que ele deveria seguir a narração já proposta na elaboração do poema. Em seus últimos livros, no entanto, encontramos a maioria dos madrigais concebidos sobre textos do próprio compositor, ou melhor, poemas escritos para servir àquele madrigal (Watkins, 1991, p. 125). Desta forma, depreende-se a liberdade com que o compositor utilizou as palavras e a extensão do enlace que existiu entre música e texto. Portanto, nos deparamos com duas situações distintas, a música feita sobre um texto já existente e o mesmo procedimento com um texto elaborado simultaneamente ao madrigal.

$\mathrm{Na}$ primeira situação, que iremos estudar com mais cuidado neste trabalho, encontramos exemplos que ilustram o processo de manipulação com o qual Gesualdo tratava os textos de outros autores. O primeiro aspecto a ser levantado é a liberdade que o compositor tinha com os poemas, possibilitando alterações no texto em prol de sua música. Esses exemplos são importantes por 
indicar os procedimentos musicais que respaldam, ou explicam, essas manipulações. O exemplo inicial consta em seu primeiro livro de madrigais na obra Tirsi Morir Voleia (madrigal XII). O texto escrito pelo poeta Giovanni Battista Guarini (1538-1612) foi muito conhecido e utilizado pelos madrigalistas da época. Sua narração poética acerca do encontro amoroso de um pastor com uma ninfa exemplifica o estilo de poema erótico, que tornou-se um dos gêneros mais populares dentre os poetas humanistas (Maniates, 1979, p. 359).

A manipulação que Gesualdo faz no texto chama a atenção por suas diferenças quando comparada aos exemplos de compositores contemporâneos a ele que também aproveitaram esse texto. Dentre estes contemporâneos destacamse: Luca Marenzio, que publicou seu madrigal sobre o mesmo texto em 1580; Wert, em 1581, e Gabrieli no ano de 1587 (McClary, 2004, p. 138).

Logo na segunda linha do poema Gesualdo inverte a ordem das palavras. Essa mudança pouco interfere no sentido do texto, mas ilustra sua liberdade perante ele.

\section{Texto original de Guarini}

"Gl'occhi mirando di colei ch'adora"
Texto do Madrigal de Gesualdo

"Mirando gli occhi di colei ch'adora"

A proximidade pessoal que Carlo Gesualdo tinha com o poeta Guarini pode ser uma explicação para a liberdade que o compositor tinha em fazer alterações no texto (Watkins, 1991, p. 37). Mas sua preocupação em estreitar cada vez mais a relação da música com o sentido do poema e, mais do que isso, colocar a música a serviço das palavras, pode nos dar uma dimensão maior da importância do texto na análise de sua obra.

O trecho do poema escolhido pelo compositor para ser musicado é ilustrativo quando comparado a outros. Todo esse madrigal que estamos tratando (madrigal XII) refere-se à primeira parte do poema, sendo que a segunda parte constituirá o próximo madrigal deste mesmo livro, o décimo terceiro. A escolha de dividir o poema em duas partes também diferencia sua obra com a de seus contemporâneos mais conhecidos, principalmente quando levado em conta o número de versos aproveitados do original. 


\section{Tirsi morir volea (Guarini)}

1 Tirsi morir volea,

2 Gl'occhi mirando di colei ch'adora,

3 Quand'ella, che di lui non men ardea,

4 Gli disse: Oime ben mio,

5 Deh non morir ancora,

$6 \quad$ Che teco bramo di morir anch'io.

7 Frenò Tirsi il desio,

8 C'hebbe di pur sua vit'allhor finire:

9 Ma sentia morte in non poter morire

10 E mentre'l guardo suo fiso tenea

11 Ne begl'occhi divini;

12 E'l nettare amoroso indi bevea;

13 La bela Ninfa sua, che già vincini

14 Sentia i messi d'Amore,

15 Disse, com occhi languidi e tremanti:

16 Mori cor mio, ch'io moro.

17 Cui rispose il Pastore:

18 Et io, mia vita, moro.

19 Cosi moriro i fortunati amanti,

20 Di morte si soave, e si gradita,

21 Che per anco morir tornaro in vita.

A narração original da história feita por Guarini consta de um poema com 21 versos. Luca Marenzio construiu seu madrigal em três partes sobre o poema completo. Wert também optou por musicar o poema todo, mas utilizou-se de apenas uma parte. Já Gesualdo dividiu seu madrigal em duas partes, mas optou por incluir apenas nove versos do poema original (Watkins, 1991, p. 141). Dessa forma, temos a primeira parte do texto no décimo segundo madrigal do livro I escrito sobre os versos 1 até o 6 . O décimo terceiro madrigal deste mesmo livro compreende a segunda parte do texto, escrito sobre os versos 7 a 9 . Ressalta-se o fato de a segunda parte de madrigal ter ao todo $31 \operatorname{compassos}^{1}$, quase o mesmo tamanho da primeira parte, que consta de 35 compassos. Esse procedimento resultou em uma segunda parte bem mais apoiada em repetições de palavras e frases do que o primeiro. Assim, o compositor teve liberdade para um desenvolvimento maior das imagens textuais que surgiriam a partir dos três

\footnotetext{
${ }^{1}$ Compassos incluídos pela edição moderna da obra. Na época não existia o uso da divisão da música, mas para esse trabalho a inclusão de compassos ajuda a demonstrar o tamanho da peça.
} 
últimos versos, demostrando para esse estudo seu processo de manipulação textual.

Ao longo de todo o processo de desenvolvimento estilístico que culminou com os madrigais mais tardios escritos sobre textos do próprio compositor, observamos exemplos de processos intermediários nos quais Gesualdo experimenta novas fórmulas de se tratar o texto. Neste ponto, encontramos os numerosos madrigais de Gesualdo com textos baseados em outros pré-existentes.

Esse procedimento amplamente utilizado pelo compositor a partir de seu segundo livro resultou para o estudo de sua obra uma dificuldade a mais, a dificuldade em se atribuir autoria aos textos. Esse tema foi discutido pelo autor Glenn Watkins em seu livro Gesualdo The Man and his Music (1991, p. 117-120) quando é feito um levantamento sobre os textos e seus respectivos autores.

Um exemplo disto está no décimo segundo madrigal do segundo livro, Sento che nel partite concebido sobre o texto de Alfonso d'Avalos. O poeta, membro de uma nobre família Napolitana, era conhecido entre os madrigalistas da época. Sua fama se deu principalmente pelo texto do madrigal // bianco e dolce signo, de Jacob Arcadelt (1507-1568), que tornou-se um dos madrigais mais conhecidos da época (Maniates, 1979, p. 302). O texto de d'Avalos utilizado como base por Gesualdo para seu madrigal foi Ancor che col partire, que também serviu a Cipriano da Rore para construção de seu madrigal homônimo. No entanto, ao contrário de Rore, Gesualdo não utiliza o poema da forma original como foi escrito, trocando inclusive o título para Sento che col partire.

\section{Alfonso d'Avalos}

Anchor che col partire lo mi sento morire Partir vorrei ogn'hor ogni momento

Tantè il piacer ch'io sento De la vita ch'aquisto nel ritorno, E cosi mill'e mille volt'il giorno Partir da voi vorrei Tanto son dolci gli ritorni miei.

\section{Gesualdo}

Sento che nel partire II cor giunge al morire, Ond'io, misero ognor, ogni momento Grido: 'Morir mi sento, Non sperando di far a voi ritorno, E cosi dico mille volte il giorno Partir io non vorrei, Se col partir accresco I dolor miei. 
Apesar de manter o esquema rítmico dos versos e também manter rigorosamente as palavras finais de cada linha, Gesualdo vai além da alteração do título e imprime sua marca pessoal até mesmo no sentido final da narração, como nos demonstra a tradução dos dois textos:

Alfonso d'Avalos

Sempre que parto

Eu me sinto morrendo

Gostaria de partir sempre, todos

Os momentos,

Tanto é o prazer que sinto

vida que adquiro no retorno,

E assim milhares e milhares de

Vezes por dia.

Eu gostaria de partir,

Tão doces são os meu retornos.

\section{Gesualdo}

Sinto que ao partir

Meu coração fica a ponto de

morrer,

Onde eu, miserável que sou, a

Cada momento,

Grito: 'Me sinto morrendo,

Não espero voltar para você.

E assim digo mil vezes ao dia.

Partir eu não quero,

Se ao partir, aumenta a minha dor.

Fica clara a intenção de Gesualdo de alterar o sentido final do poema na sua versão. No original de d'Avalos, utilizado por Rore em seu madrigal, encontramos a narração de um sentimento de dor por uma partida que acaba sendo sublimado pela felicidade do reencontro, de forma que o personagem acaba por pedir pela despedida antevendo o prazer da volta. Já na versão de Gesualdo essa compensação da dor da partida pelo reencontro não ocorre, pois o personagem não espera pelo reencontro. Neste caso, o seu pedido é de não querer partir.

Outra obra que está claramente nesta fase intermediária de se tratar o texto encontra-se no quinto livro, em seu terceiro madrigal. 0 texto de Itene, $O$ miei sospiri já havia sido utilizado por Luzzasco Luzzaschi em seu madrigal Itene mie querele (Einstein, 1971, p. 704). As diferenças do poema não ficam restritas ao título, mas em toda a sua construção. No entanto, todo o esquema rítmico dos versos, as inúmeras semelhanças de sentido, a temática geral do poema, somadas à atribuição anônima dada a ambos os textos, nos levam a concluir que Gesualdo se baseou no texto utilizado por Luzzaschi para construir o seu madrigal, por mais que não existam documentos do compositor que comprovem isso. A comparação pode ser analisada abaixo: 


\section{Luzzaschi}

Itene mie querele

Precipitose a volo

A lei che m'è cagion d'eterno duolo.

Ditele per pietà ch'ella mi sia

Dolcemente crudele,

Non crudelmente ria

Ch'l dolorosa stride

Cangerò lieto in amorosi stride

\section{Gesualdo}

Itene, o miei sospiri

Precipitate 'I volo

A lei che m'è cagion d'aspiri martiri.

Ditele, per pieta, del mio gran duolo;

C'ormai ella mi sai

Come bella ancor pia,

Che l'amaro mio pianto

Cangerò, lieto, in amoroso canto

As conclusões quanto às diferenças promovidas por Gesualdo em seu texto, podem ser conferidas a partir da tradução comparativa:

\section{Luzzaschi}

Ide minhas queixas

Apressado em voar

A ela que é a causa de minha eterna dor

Diga-a por piedade, que ela me seja

Docemente cruel

Não ria cruelmente

Que o doloroso grito

Transformou-se alegremente em gritos de amor.

\section{Gesualdo}

Ide, oh meus suspiros

Precipita-se em vôo

A ela que é a causa de meus martírios

Diga-a, por piedade, de minha grande dor.

Que agora ela seja

Tão piedosa quanto bela,

Que o amargo de meu pranto

Transforme-se, alegremente, em amoroso canto.

Através dessas alterações o compositor conseguiu manipular o poema a ponto de construir um madrigal com uma temática mais dolorosa do que o texto inicial pressupunha, mantendo assim as características típicas de sua obra - o conflito e a dor presentes no texto e, consequentemente, refletidos na música.

O procedimento descrito acima evidencia o processo de amadurecimento do compositor e a forma independente que ele passou a usar na construção textual de suas obras. Através desse processo, Gesualdo foi abandonando aos poucos a forma rígida do soneto clássico para usufruir de textos que lhe oferecessem mais liberdade (Balsano, Walker, 1988, p. 21). O desenvolvimento disto pode ser comprovado quando verificamos as diferenças dos poemas presentes nos primeiros madrigais em comparação aos publicados nos últimos livros. Resumidamente, temos o abandono da poesia a duas partes para, no geral, textos em uma única parte sem moldes pré-definidos. A principal diferença 
encontra-se na substituição dos poemas de seus contemporâneos humanistas por textos próprios concebidos especialmente para aqueles madrigais.

As diferenças de palavras e as alterações nas construções das frases quando não resultam em alterações drásticas do sentido do poema são indícios de que o compositor procurava sentenças e sons de palavras adequados para sua música. Para isso, ele muitas vezes trabalhava o texto sem se importar com a intenção do poeta.

Essa procura pelo melhor termo, muitas vezes feita a revelia das escolhas do autor do texto, evidencia o processo de concepção da obra pelo compositor, colocando em primeiro plano a relação música/texto. Esse procedimento torna-se imprescindível no momento da análise e do entendimento da obra de Gesualdo e pode ser atestado por documentos de época que comprovam a construção desta prática. Um desses documentos que nos ajuda a definir e a entender essa relação poética do madrigal italiano, é o tratado escrito pelo humanista e cardeal veneziano Pietro Bembo (1470-1547) intitulado Prose dela volgar lingua, publicado pela primeira vez em 1525 (Bembo, 1525). Bembo, que era membro de uma família nobre da Itália, dedicou essa obra a discutir e entender a língua italiana e sua relação com a música. Para tal objetivo, o humanista usou como modelo a poesia de Petrarca (1304-1374) e a prosa de Boccacio (1313-1375). Através de sua análise sobre o tema que foi feita contemporaneamente à obra dos grandes madrigalistas italianos, depreendemos alguns conceitos importantes na análise da escrita poética dessas obras.

Segundo o autor, a poesia de Petrarca tornou-se um modelo de escrita poética no século XVI e a partir dela elaboraram-se as bases para uma boa escrita musical. Essa boa escrita precedia três estágios principais; o som, o número (ritmo) e a variação, sem as quais não se atingia um bom resultado na escrita (Bembo, 1525, p. 324). Portanto, a base para essas composições era o texto escolhido. Como bem define o escritor Pietro Misuraca em seu livro sobre Carlo Gesualdo que também trata a relação textual através dos escritos de Pietro Bembo (2000, p. 14): “a poesia é a música em estado embrionário". ${ }^{2}$

\footnotetext{
${ }^{2}$ La poesia è musica allo stadio embrionale
} 
De acordo com a visão de Bembo, a escolha das palavras o cuidado com seu ritmo e sua disposição nos versos musicais seriam os ingredientes fundamentais para se alcançar a persuasão na música. Persuasão, para Bembo, é uma virtude musical oculta que tem o propósito de fazer todos sentirem e pensarem a mesma emoção escrita pelo compositor: “... aquela oculta virtude que, estando em qualquer voz, move os demais a sentirem aquilo que leem."3 (Bembo, 1525, p. 342).

Através da descrição desses conceitos musicais encontrados neste tratado, conseguimos esclarecer de certo modo o ideal estético que prevalecia na primeira parte do século XVI, e compreender as bases nas quais Gesualdo construiu seus parâmetros estéticos.

Outra característica importante na análise musical de Gesualdo está na maneira como o compositor elabora suas seções, principalmente por encontrarmos ao longo dos madrigais duas formas principais de construção. Uma delas é a divisão em blocos de textos, com as frases e os versos delimitando o tamanho das seções. Nesta forma de conduzir a narração o compositor se utiliza de recursos musicais para ressaltar os finais de frases e versos. Esses recursos podem ser cadências melódicas ou harmônicas em determinadas palavras, alteração da textura musical de uma frase para outra normalmente contrastante ou alterações rítmicas que demonstrem a mudança das frases.

Um exemplo para essa escrita em blocos está na figura 1 abaixo retirada do décimo primeiro madrigal do primeiro livro de Gesualdo. O madrigal intitulase $O$ dolce mio martirire.

3 "...quella occulta virtú che, in ogni voce dimorando, commuove altrui ad assentire a ciò che egli legge." 
Figura 1 - O dolce mio martire - Livro 1 - c. 10 a 12

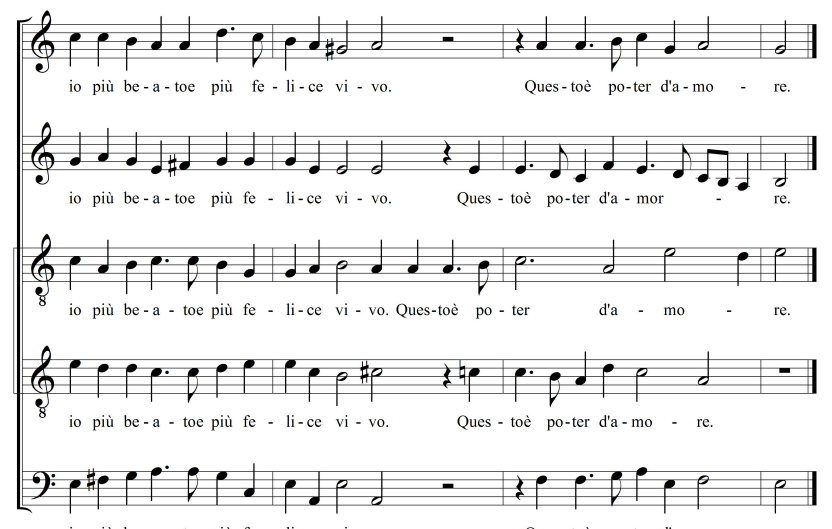

io più be - a - toe più fe - li-ce vi - vo.

Ques - toè po-ter d'a-mo - re.

A segunda forma encontrada de manipulação das seções textuais caracteriza-se pela intersecção dos versos e das frases. Nesta forma de manipulação Gesualdo cria seções interligadas que vão sucedendo as frases textuais sem interrupção, ou melhor, deixando as delimitações para pontos específicos da narração textual. Esse processo resulta em seções maiores no tamanho e em menores quantidades ao longo da obra. Existem exemplos dessa escrita nos primeiros livros do compositor, mas sua ocorrência aumenta na escrita mais madura das últimas fases. A narração promovida através de seções maiores e mais complexas passa a ser comum nas fases finais por estar de acordo com as demais características dessa fase, com a forma musical das obras menos rígidas e a narração do texto mais livre.

Na figura 2, colocada abaixo, e que consta do quinto livro de madrigais, cujo título é $O$ dolorosa gioa, encontramos o procedimento descrito acima. As frases sucessivas do poema são apresentadas na mesma seção, ou melhor, sem demarcações de seções, resultando em um madrigal escrito a uma só parte interligada.

Além da identificação de dois procedimentos utilizados pelo compositor, os exemplos discutidos acima sobre as divisões de seções na obra de Gesualdo demonstram possíveis influencias de outras formas do Renascimento na obra do madrigalista. Demonstram também, a mudança de procedimento que que ocorreu lentamente ao longo de sua obra. A importância desta discussão e suas 
possíveis conclusões está na compreensão do amadurecimento da escrita do compositor e suas implicações no entendimento geral da obra.

Figura 2 - O dolorosa gioa - Livro 5- c. 1 a 9

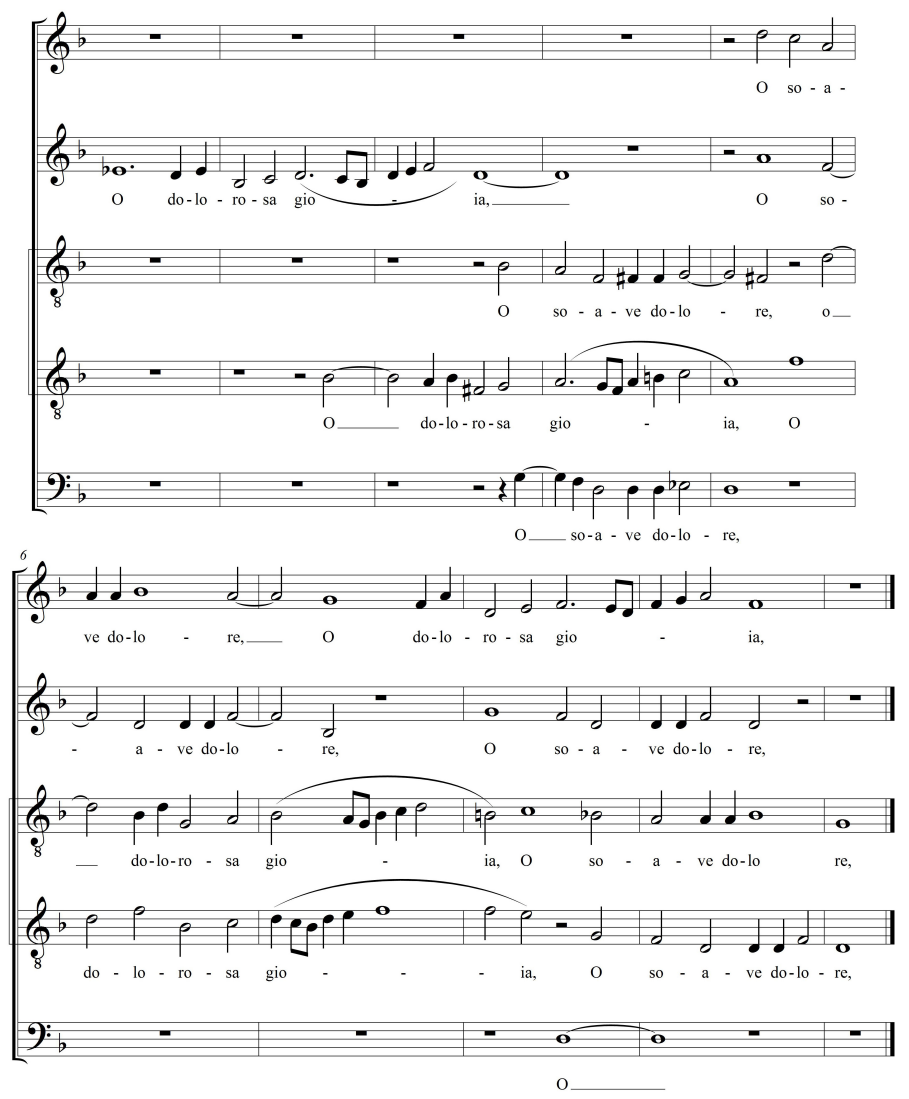

Diante desse assunto, o autor Glenn Watkins em seu livro sobre a obra de Gesualdo discute essas duas formas de divisão textual e as influências identificadas neste procedimento. Para ele, a escrita em blocos, mais comum nas fases iniciais do compositor, é uma influência de gêneros correlatos a frottola e a canzone. Enquanto que as seções maiores e menos delimitadas demonstram a influência do moteto sacro na escrita madrigalista:

A importância do moteto para o madrigal, ter afastado a rígida associação entre verso e frase o que caracterizava a frottola, canzone e o início do 
madrigal, para relações mais flexíveis no madrigal tardio, não deve ser super estimada ${ }^{4}$ (Watkins, 1991, p. 117).

Atribuir às formas seculares que remontam ao início do Renascimento, como a frottola e a canzone, a influência da escrita textual em blocos explica de forma convincente esta prática. É possível identificar claramente essa influência nos dois primeiros livros de madrigais de Gesualdo, enquanto que nos observa-se abandono deste procedimento.

A canzone ilustra bem a influência nos madrigais do compositor. Essa forma caracteriza-se por ser basicamente estrófica, podendo ter de duas a nove estrofes por poema. Esse modelo poético foi especialmente cultivado por Petrarca (1304-1374) e Boccacio (1313-1375) no século XIV, mas sua influência atingiu toda uma geração de madrigalistas no século XVI (McClary, 2004, p. 53-54). As 29 canzoni que Petracarca escreveu tornou-se o modelo que mais influenciou os demais poetas. A poesia deveria ter duas partes, sendo a primeira chamadas de piedi com o esquema de $A B C / B A C$, enquanto que a segunda parte, chamada sirima, eram pensadas de forma única com as subdivisões internas cDdeE. O elemento mais característico na forma das Canzoni é a rima de ligação que deveria existir entre a última linha do segundo piedi e a primeira linha da sirima.

Diante destas características chama a atenção o fato de encontrarmos um madrigal do primeiro livro de Gesualdo escrito exatamente dentro da forma de canzone. O texto escrito por Guarini, Baci soavi e cari, está dividido em duas partes que correspondem aos dois primeiros madrigais deste livro. A divisão das rimas que caracterizam a forma canzone foi completamente respeitada pelo compositor, como demonstra o esquema abaixo:

\section{Primeira parte}

(A) Baci soavi e cari,

B) Cibi de la mia vita,

(C) C'or m'involate, or mi rendete il core!

(A) Per voi convien ch'impari

(B) Come un' alma rapita

(C) Non sente il duol di morte e pur si more.

\footnotetext{
${ }^{4}$ The importance of the motet for the madrigal, as it moved away from the more rigid association between verse and frase which characterized the frótola, canzone, and early madrigal, cannot be over-estimated.
} 


\section{Segunda parte}

(c) Quanto há di dolce Amore,

(d) Perchè sempre io vi baci,

(e) O dolcissime rose

(e) In voi tutto ripose,

(D) Deh, s'io potessi ai vostri dolci baci

(f) La mia vita finire,

(f) O che dolce morire!

A simetria dos versos da primeira parte, o piedi (C e C) e a coincidência da rima destas duas frases com a frase inicial da segunda parte, sirima (c), não deixa dúvidas de se tratar de uma canzone.

O que chama atenção neste madrigal é o fato de sabermos que na época de Gesualdo a forma canzone não era mais comum, como no início do século. Essa informação é atestada pelo próprio Glenn Watkins em seu livro (1991, p. 112): “Na época de Gesualdo, no entanto, a estrutura estrófica da canzone já estava fora de moda". 5

Porém, sua presença neste madrigal atesta a influência das formas seculares na escrita madrigalista do século XVI e, em especial para esse estudo, sua influência na obra de Carlo Gesualdo.

No entanto, ao levar em consideração a produção de motetos ao longo do Renascimento identifica-se a fragilidade da atribuição dada a essa forma da influência no Madrigal Tardio. A escrita do moteto também sofreu transformações e influências ao longo do período inclusive da escrita madrigalista e, principalmente, do ideal humanista de música e texto. Essas transformações resultaram em uma produção heterogênea de motetos, com características distintas entre si. Diante desses fatos, torna-se mais concreto considerar que a escrita do madrigal italiano em sua fase tardia influenciou a escrita dos motetos do que o contrário, como considerou a citação do autor Glenn Watkins.

Independente da discussão sobre a influência ou não do moteto sobre o madrigal, esta análise traz a pesquisa a comprovação de que as formas iniciais do Renascimento influenciaram a relação entre música/texto nas primeiras fases da escrita do compositor. Porém, essa influencia diminui ao longo de suas fases posteriores e não é mais percebida em suas obras mais tardias. A explicação para

\footnotetext{
${ }^{5}$ By Gesualdo's time, however, the sctructure canzone stanza was already out of vogue.
} 
a mudança de procedimento está no amadurecimento desta mesma relação, música/texto, o que comprova sua importância na elaboração deste repertório.

\section{Conclusão}

A partir do estudo realizado através deste artigo procurou-se demonstrar a importância da relação música/texto na escrita dos madrigais italianos. No caso específico da obra de Carlo Gesualdo, conclui-se que: na fase inicial de sua escrita, o compositor utilizava textos de poetas conhecidos da época para construir seus madrigais, fazendo pequenas alterações de palavras para ajustar às suas intenções musicais. Nas fases intermediárias de sua carreira, aumenta o número de textos do compositor apoiados em poemas conhecidos. Desta forma, Gesualdo adaptava um texto escrito por outro poeta à suas necessidades musicais, alterando-o quase completamente. E, por fim, na fase madura de sua obra, o compositor passa a escrever ele mesmo os textos de seus madrigais.

Portanto, a relação música/texto na obra de Carlo Gesualdo se estreita ao longo de sua vida a tal ponto que não permite mais a interferência de outro poeta senão o próprio compositor.

\section{Referências}

ATLAS, Allan. W. Renaissance Music Music in Western Europe, 1400-1600. New York: W.W. Norton \& Company, 1998.

BAlSANO, Maria A. WALKeR, Thomas. Tasso La Musica, I Musicisti. Firenze: Leo S. Olschki Editore, 1988.

BEMBO, Pietro. Prose dela volgar língua, libro II, in Opere in volgare, a. c. di M. Marti. Firenze: Sansoni, 1525.

BROWN, H. M. Music in the Renaissance. New Jersey: Prentice-Hall, Inc, 1976.

EINSTEIN, Alfred. The Italian Madrigal. New Jersey: Princeton University Press, first edition, Paintition, 1971.

HAUSER. Arnold. Maneirismo: A Crise da Renascença e a Origem da Arte Moderna. Tradução: Magda França; Revisão: J. Guinsburg. São Paulo: Perspectiva, Ed. Da Universidade de São Paulo, 1976. 
HOCKE, Gustav R. Maneirismo na Literatura. Tradução: Fernando de Moraes Barros. São Paulo: Perspectiva, 2011.

LOWINSKY, Edward. E. Tonality and atonality in sixteenth-century Music. California: University of California Press, 1962.

MANIATES, Maria. R. Mannerism in Italian music and culture, 1530-1630. Manchester: Manchester University Press ND, 1979.

McCLARY, Susan. Modal Subjectivities. California: University of California Press, 2004.

MISURACA, Pietro. Carlo Gesualdo Principe di Venosa. Palermo: L’Epos, 2000.

ROWLAND, Daniel B. Mannerism - Style and Mood. London: Yale University Press, 1964.

SHEARMAN, John. O Maneirismo. Tradução de Octavio Mendes Cajado. São Paulo: Editora da Universidade de São Paulo, 1978.

WATKINS, Glenn. Gesualdo, The Man and His Music. 2.ed. Oxford: Clarendon Paperbacks, 1991. 